\section{Sreenivas Alampalli}

Transportation Research \&

Development Bureau

New York State Department

of Transportation

1220, Washington Avenue

Albany, NY 12232-0869, USA

E-mail:

salampalli@gw.dot.state.ny.us

\title{
Dynamic Response of Wall Backfill Retaining System
}

\author{
Ahmed-W. Elgamal \\ University of California at San Diego \\ San Diego \\ CA 92093-0085, USA \\ E-mail: elgamal@ucsd.edu
}

\begin{abstract}
An in situ full-scale test is conducted to measure the dynamic response of a long cantilever wall that retains backfill soil. The recorded modal parameters of this retaining wall exhibited significant similarity to those of a clamped cantilever plate (rather than those of a cantilever beam or plane-strain analysis). Such a three-dimensional (3-D) response pattern is not accounted for by current analysis procedures. A simple 3-D finite element model is employed to further analyze the observed resonant configurations. The results indicate that such configurations play an important role in the seismic response of wall backfill soil systems of variable height, such as wing walls supporting highway approach ramps.
\end{abstract}

\section{INTRODUCTION}

Retaining walls are built for the purpose of supporting an adjacent soil mass or backfill. The magnitude of earthquake-induced loads on such structures depends on the backfill and foundation properties, earthquake motion characteristics, and structural wall properties. Damage to retaining wall systems due to seismic activity is often reported in the literature (Jennings, 1971; Seed and Whitman, 1970; Sitar et al., 1995; Tatsuoka et al., 1996; Whitman and Christian, 1990).

A number of analytical and numerical models have been proposed to investigate the earthquake response of cantilever retaining walls (Alampalli, 1990; Whitman, 1991). In these models, earthquake response is assumed to be uniform along the wall, and such wall backfill systems are modeled under 2-dimensional (2D) or plane-strain conditions (Arias et al., 1981; Matsuo and Ohara, 1960; Velestos et al., 1995; Wood, 1973, 1975).

A large and growing body of full-scale dynamic tests on civil engineering structures has been reported in the literature (Alampalli et al., 1995; Calciati et al., 1977; Douglas and Reid, 1982; Keightley, 1966; Paskalov et al., 1977). However, very few full-scale tests have been performed on retaining wall soil systems (Aliev et al., 1973; Amano et al., 1956; Chang et al., 1990; Fukuoka and Imamura, 1984). During a pilot full-scale test on a retaining wall system (Alampalli, 1990; Elgamal et al., 1990), it was found that 
modal spatial variation was displayed along the wall length as well as its height. Modes were found to bear significant similarity to those of a clamped cantilever plate rather than those of a cantilever beam (planestrain analysis). Such a 3-D response pattern was further analyzed during a more recent forced vibration frequency sweep test (Elgamal et al., 1996).

In the following section, the experimental testing program is summarized. A number of salient experimental observations are presented. The recorded dynamic response is analyzed within a simple analytical and numerical framework to investigate the observed 3-D response mechanisms.

\section{EXPERIMENTAL STUDY}

The test structure was a long wall (140 ft) of varying height from 4.6 to $10 \mathrm{ft}$ and a thickness of $1.3 \mathrm{ft}$ (Fig. 1). This wall supported an elevated parking lot. A construction joint was located at about $75 \mathrm{ft}$ from the short end of the wall (Fig. 1).

A typical test configuration is shown in Fig. 2. It consists of a dynamic signal analyzer (HP model HP3562A) to obtain real-time frequency domain representations of the recorded signals, a large 12-lb weight sledge hammer with a force transducer for excitation (PCB model 086B50), an accelerometer for response measurement (PCB model 39C), amplifiers, signal conditioners, and a microcomputer with a floppy and hard disk drive (HP model 300, series 9000). At the beginning of testing, reciprocity was verified by comparing frequency response functions (FRF) obtained through interchanging input and output locations. During a test, measurement locations were chosen to reflect the behavior of the strucutre in the modes of interest. Only the dynamic wall response perpendicular to its plane was measured (Alampalli, 1990).

Excitation hammer input was imparted at sampling points (measurement locations) and the resulting acceleration output was measured at a stationary point (Alampalli, 1990). For each measurement point, an input-output FRF was computed by the analyzer, which also performed signal digicization using appropriate antialiasing filters, such that,

$$
\operatorname{FRF}(f)=G_{y x}(f) / G_{x x}(f),
$$

where $G_{y x}(f)$ is the cross power sectrum of output and input signals, $G_{x x}(f)$ is the auto power spectrum of the input signal, and $f$ is the frequency variable. An exponential window (filter) was used on the structural vibration response and a force window was used on the hammer excitation. Mode shapes were extracted using the peak curve-fitting technique (Ewins, 1984). For any sampling point, the process was repeated and the average of a number of FRFs was finally stored as the input-output transfer function for this point. Inspection of the coherence function, $\gamma$ (Ewins, 1984) dictated the number of FRFs to be averaged, where

$$
\gamma^{2}(f)=G_{y x}(f) G_{x y}(f) /\left(G_{x x}(f) G_{y y}(f)\right),
$$

in which $G_{y y}(f)$ is the auto power spectrum of the output signal. The coherence function assures consistency of the obtained data. A coherence of zero denotes that input and output are unrelated, whereas a coherence of unity denotes that they are related with no interference or noise effects. In this study, a highly satisfactory coherence of 0.95 or greater was always achieved. A modal parameter estimation package (modal 3.0 SE), developed by Structural Measurement Systems (SMS, 1987), was employed for extraction of modal parameters (linearity and reciprocity for the test structures is assumed).

Transfer functions of 178 measurement locations along the exposed side of the wall were measured (Alampalli, 1990). From these transfer functions, resonant frequencies and associated mode shapes were obtained. A number of these mode shapes are shown in Fig. 3(a). A rough estimate of damping ratios suggested a value of about $8 \%$ for most of these modes.

In a more recent test, the same structure was tested in the low frequency range (up to $17 \mathrm{~Hz}$ ) of significance for earthquake-type excitation (Elgamal et al., 1996). A 5000-lb harmonic shaker was employed in a frequency sweep mode. The observed modal configurations [Fig. 3(b)] also clearly displayed the above mentioned 3-D response effects.

It may be noted that the resonant wall configurations (Fig. 3) mimic that of a cantilever clamped plate. Along the length, the amplitude gradually increased with the increase in free cantilever wall height (Fig. 3). Such a 3-D response pattern is not accounted for by current analysis procedures. Hence, a simple 3-D finite element model was employed to further analyze the observed resonant configurations and their potential contribution to seismic response of wall backfill soil systems.

\section{NUMERICAL STUDY}

A simple finite element model was employed to investigate the conditions associated with $3-\mathrm{D}$ seismic retaining wall response. The wall was modeled using 3-D brick elements. A system of springs along the 


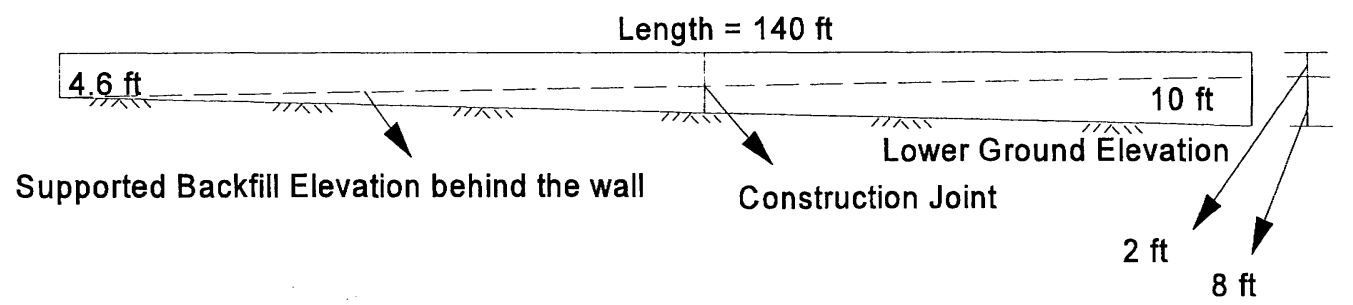

FIGURE 1 Schematic of tested wall (elevation view).

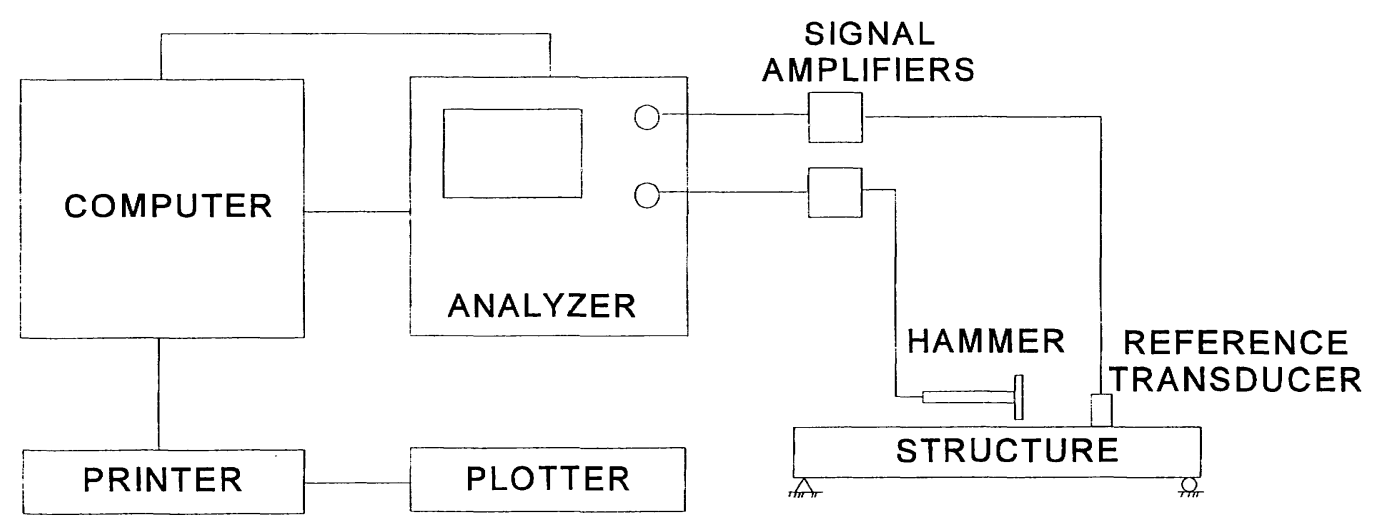

FIGURE 2 General test setup for impact hammer test.

Table 1. Natural Frequencies and Modal Participation Factors of 30-ft Plane-Strain Wall

\begin{tabular}{ccc}
\hline $\begin{array}{c}\text { Mode } \\
\text { No. }\end{array}$ & $\begin{array}{c}\text { Frequency } \\
(\mathrm{Hz})\end{array}$ & Modal \\
\hline 1 & 5.581 & 0.50285 \\
2 & 17.186 & -0.18740 \\
3 & 31.237 & -0.00016 \\
4 & 47.088 & 0.12500 \\
5 & 90.638 & -0.03567 \\
\hline
\end{tabular}

wall face represented the backfill soil. In this model, the following parameters were employed: Young's modulus $=4 \times 10^{8} \mathrm{lb} / \mathrm{ft}^{2}$, Poisson's ratio $=0.15$, density $=145 \mathrm{lb} / \mathrm{ft}^{3}$, and soil spring constant $=$ $1 \times 10^{5} \mathrm{lb} / \mathrm{ft}^{3}$.

The response of four long walls (fixed at the base and free along the boundaries) was studied: a wall of 30-ft height and 3-ft thickness, using plane-strain analysis; a wall of 150-ft length, 3-ft thickness, and 30$\mathrm{ft}$ uniform height; a wall of 150-ft length, 3-ft thickness, and height varying from $40 \mathrm{ft}$ at one end to $20 \mathrm{ft}$ at the other end; and a wall of $150-\mathrm{ft}$ length, 3 - $\mathrm{ft}$ thickness, and height varying from $40 \mathrm{ft}$ at one end to $10 \mathrm{ft}$ at the other end. In all cases, the retained soil was assumed to extend throughout the
Table 2. Natural Frequencies and Modal Participation Factors of 3-D Wall with 30-ft Uniform Height

\begin{tabular}{rcc}
\hline $\begin{array}{c}\text { Mode } \\
\text { No. }\end{array}$ & $\begin{array}{c}\text { Frequency } \\
(\mathrm{Hz})\end{array}$ & Modal Participation Factor* \\
\hline 1 & 5.020 & 1.407 \\
2 & 5.083 & 0 \\
3 & 5.305 & 0 \\
4 & 5.793 & 0 \\
5 & 6.703 & 0 \\
6 & 8.190 & 0 \\
7 & 10.311 & 0 \\
8 & 13.084 & 0 \\
9 & 14.852 & 0 \\
10 & 16.466 & 0 \\
11 & 16.469 & 0 \\
12 & 17.238 & 0.720 \\
13 & 17.375 & 0 \\
14 & 17.840 & 0 \\
15 & 18.621 & 0 \\
\hline
\end{tabular}

* Motion perpendicular to wall face.

wall height and length. Natural frequencies and modal participation factors (perpendicular to the wall face) were computed by an appropriate eigenvalue solver (Tables 1-4). Mode shapes for this 3-D finite element 
(a)

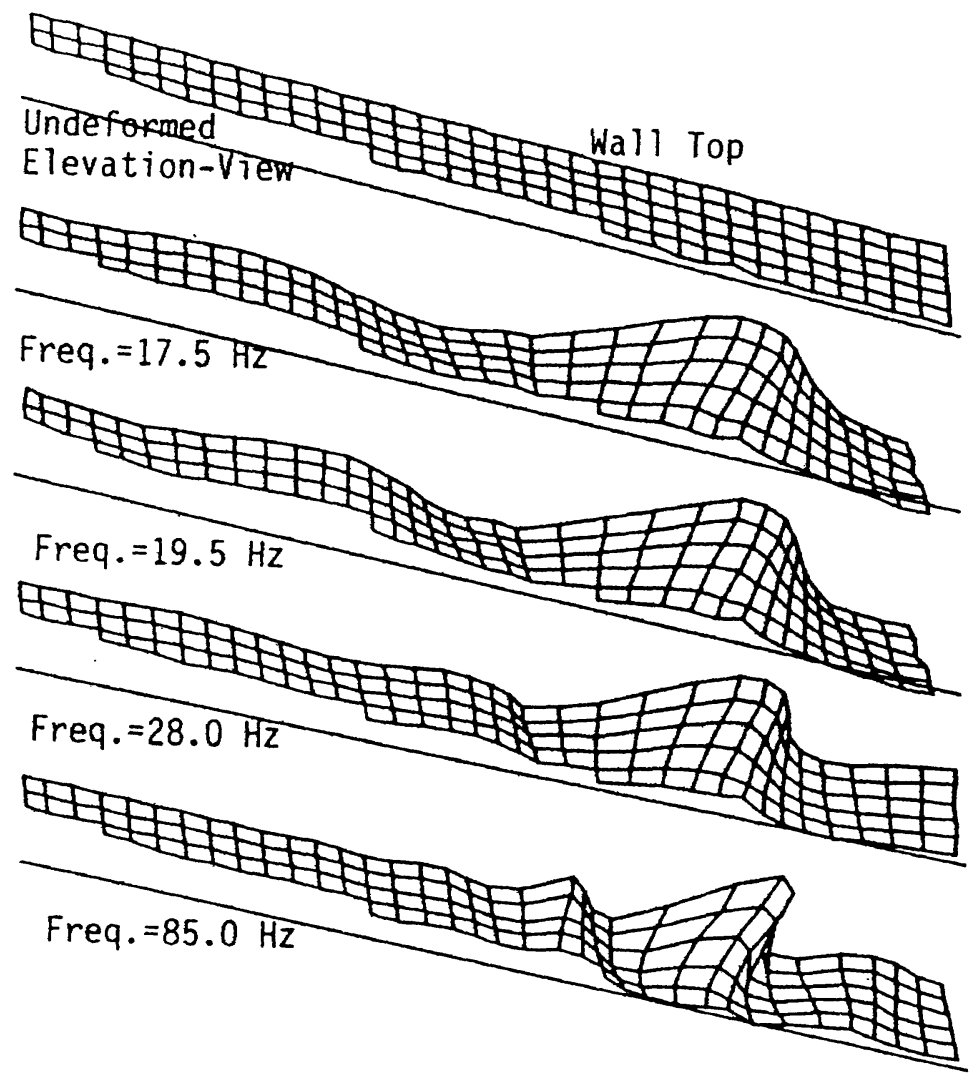

(b)
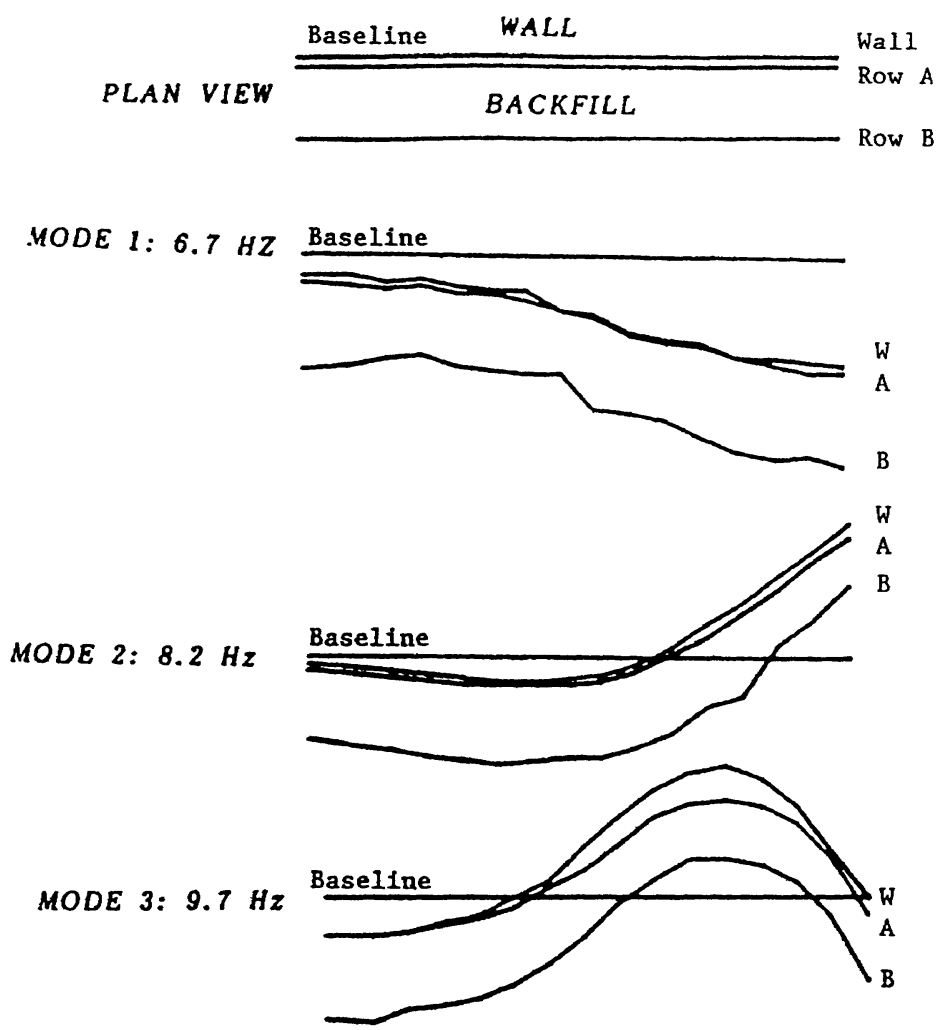

FIGURE 3 Selected resonant configurations of wall system. (a) In situ impact hammer test and (b) In situ frequency sweep test. 
Mode No.

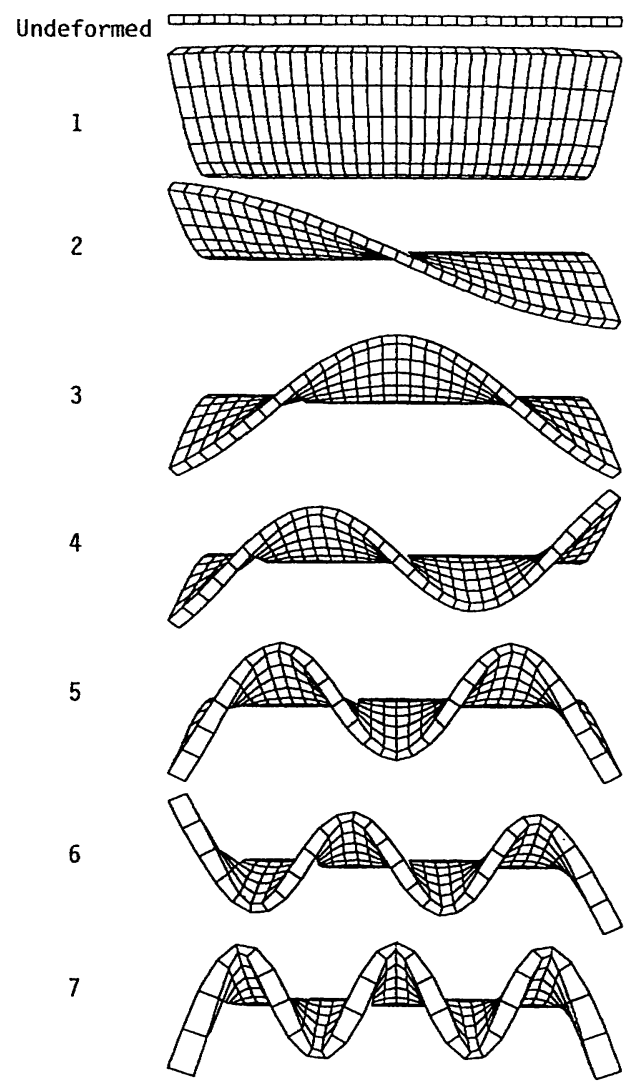

Mode No.

8

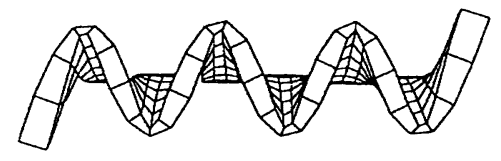

9

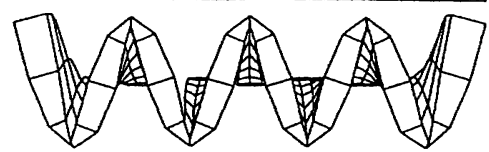

11

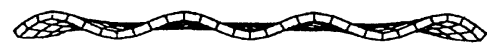

12

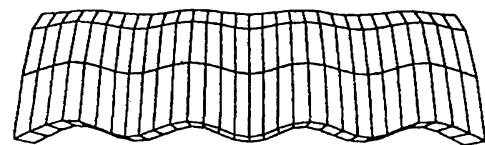

13

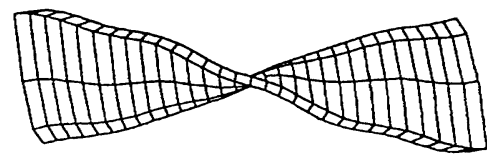

14

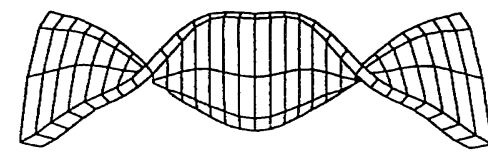

15

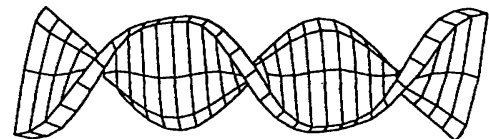

FIGURE 4 Mode shapes of 30-ft uniform height wall (in plan view).

model are shown in Figs. 4-6. These results reveal the following.

\section{Uniform Height Wall}

The mode shapes of the uniform height wall are shown in Fig. 4, and corresponding modal participation factors are shown in Table 2. (Mode 9 is a longitudinalvertical mode of negligible modal participation factor; hence, attention is focused herein on the other modes.) Only modes 1 and 12 have a significant modal participation factor in the direction perpendicular to the wall face. These modes are the first and second modes along the height, rerspectively, and correspond to modes 1 and 2 of the plane-strain idealization (Table 1).

All other 3-D modes were essentially perfectly symmetric or perfectly antisymmetric along the wall height (Fig. 4). Hence, modal participation factors corresponding to these modes were zero (see Table 2). Such modes would only be excited by nonuniform input ground motion components along the wall length. In general, such motions during an earthquake may be of negligible effect, except for walls of large length.
Table 3. Natural Frequencies and Modal Participation Factors of Wall with Height Varying Linearly from 40 to $20 \mathrm{ft}$

\begin{tabular}{rcc}
\hline $\begin{array}{c}\text { Mode } \\
\text { No. }\end{array}$ & $\begin{array}{c}\text { Frequency } \\
(\mathrm{Hz})\end{array}$ & \begin{tabular}{c} 
Modal Participation Factor* \\
\hline 1
\end{tabular} \\
\hline 4.459 & 2.214 \\
2 & 4.806 & -1.172 \\
3 & 5.271 & 0.694 \\
4 & 5.833 & -0.376 \\
5 & 6.752 & 0.123 \\
6 & 8.255 & 0 \\
7 & 10.391 & 0 \\
8 & 12.361 & 0 \\
9 & 12.965 & -0.807 \\
10 & 13.173 & -0.196 \\
11 & 15.422 & -0.523 \\
12 & 16.552 & 0 \\
13 & 17.594 & -0.360 \\
14 & 19.492 & 0 \\
15 & 19.815 & 0.284 \\
\hline
\end{tabular}

${ }^{*}$ Motion perpendicular to wall face. 


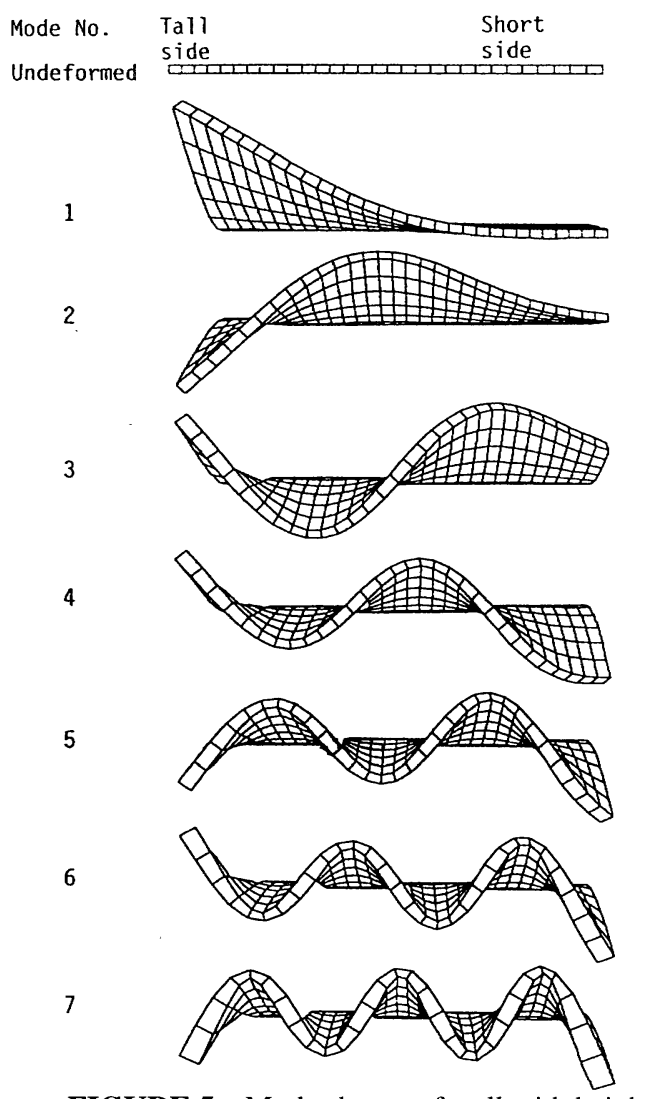

Mode No.

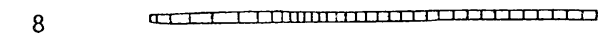

9

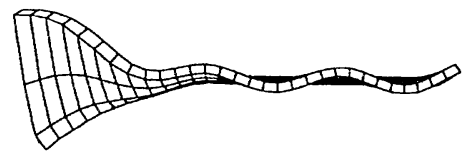

10

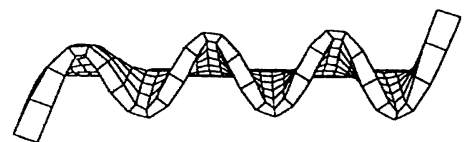

11

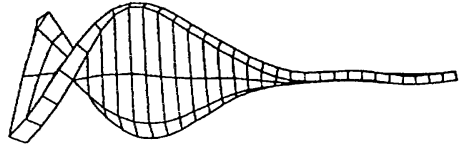

12

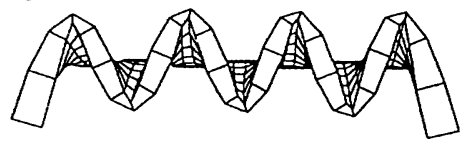

13

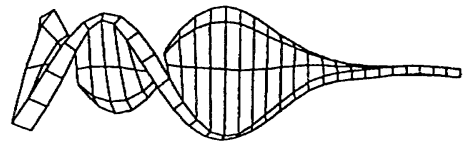

14

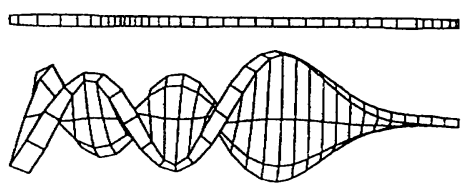

FIGURE 5 Mode shapes of wall with height varying linearly from 40 to $20 \mathrm{ft}$ (in plan view).

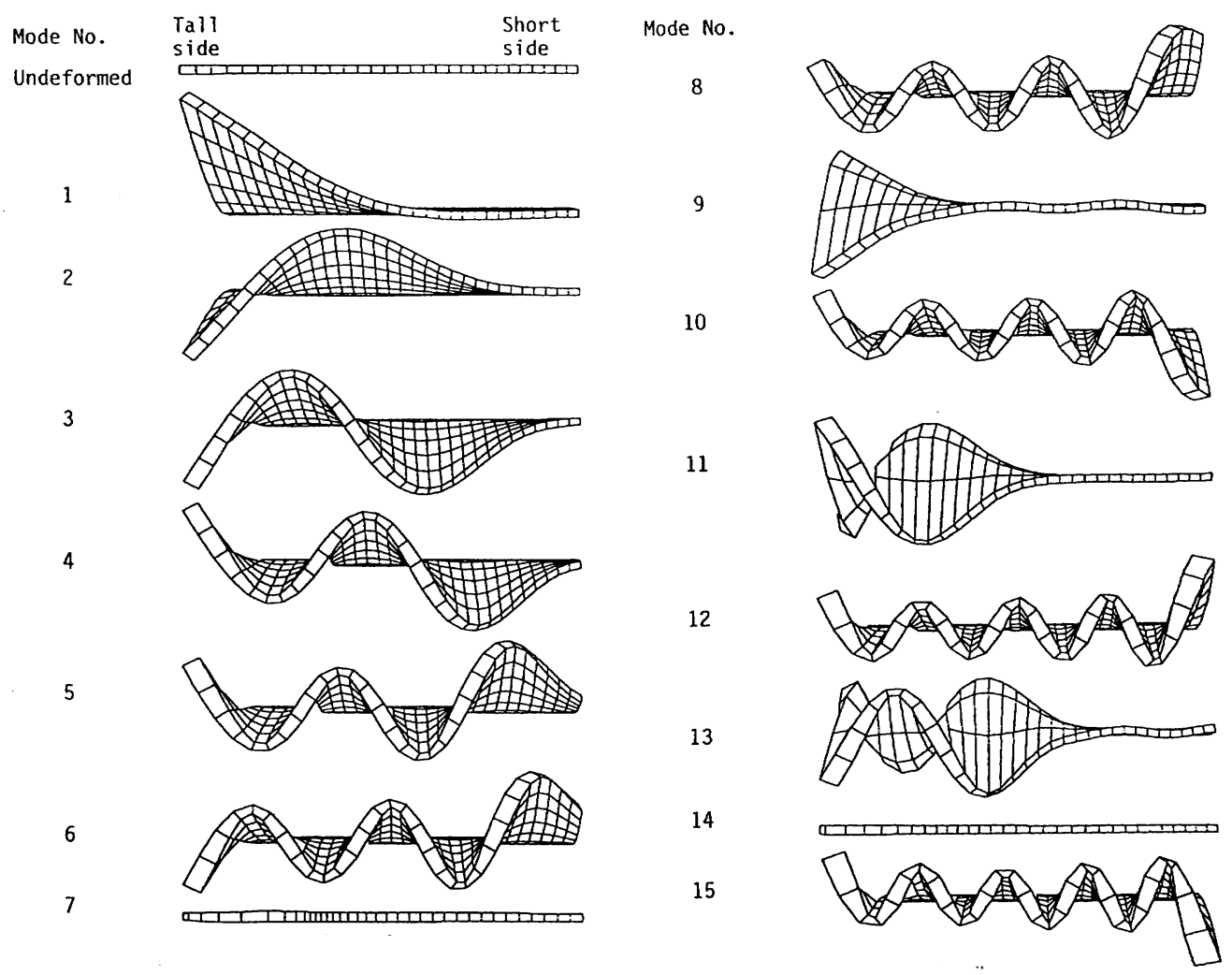

FIGURE 6 Mode shapes of wall with height varying linearly from 40 to $10 \mathrm{ft}$ (in plan view). 
Table 4. Natural Frequencies and Modal Participation Factors of Wall with Height Varying Linearly from 40 to $10 \mathrm{ft}$

\begin{tabular}{rcc}
\hline $\begin{array}{c}\text { Mode } \\
\text { No. }\end{array}$ & $\begin{array}{c}\text { Frequency } \\
(\mathrm{Hz})\end{array}$ & Modal \\
\hline 1 & 4.473 & 2.185 \\
2 & 5.038 & -1.135 \\
3 & 5.938 & 0.687 \\
4 & 7.211 & -0.494 \\
5 & 8.843 & 0.381 \\
6 & 10.765 & -0.293 \\
7 & 12.546 & 0 \\
8 & 12.925 & 0.213 \\
9 & 13.221 & -0.974 \\
10 & 15.960 & -0.139 \\
11 & 16.680 & 0.523 \\
12 & 18.573 & 0 \\
13 & 19.988 & -0.328 \\
14 & 21.089 & 0 \\
15 & 23.325 & 0 \\
\hline
\end{tabular}

* Motion perpendicular to wall face.

\section{Nonuniform Height Walls}

Mode shapes of these two walls are shown in Figs. 5 and 6 , and the corresponding modal participation factors are shown in Tables 3 and 4. (Modes 8 and 14 of Table 3 and Fig. 5 and modes 7 and 14 of Table 4 and Fig. 6 are vertical-longitudinal modes of negligible modal participation factors; hence, attention is focused herein on the other modes.) In the two nonuniform height cases, it is evident that all modes significantly depart from perfect symmetry or asymmetry. This departure increased with the increase in height differential between the left and right ends of the wall. Thus, all modes show significant nonzero modal participation factors. Uniform ground motion will consequently excite all these modes. Under earthquake excitation, any of these modes may play a significant role as dictated by the nature of input ground excitation.

Based on the above discussions, it might be concluded that the $30-\mathrm{ft}$ plane-strain idealization is only effective in matching the first mode of a variable height wall (such as the 40-20 case) and essentially misses all other modes of vibration ( Table 3).

\section{Steady-State Forced Response}

For above mentioned four wall models, a steady-state forced response analysis was also performed by applying an inertial load in the direction perpendicular to the wall plane. A frequency sweep was conducted in the $0-25 \mathrm{~Hz}$ range at an interval of $0.05 \mathrm{~Hz}$
Table 5. Natural Frequencies of Uniform Height Wall Using Plate Theory

\begin{tabular}{ccccc}
\hline & & \multicolumn{3}{c}{ Frequency (Hz) } \\
\cline { 3 - 5 } & & $\mathrm{H}=12 \mathrm{ft}$ & $\mathrm{H}=24 \mathrm{ft}$ & $\mathrm{H}=24 \mathrm{ft}$ \\
Mode & & $\mathrm{L}=140 \mathrm{ft}$ & $\mathrm{L}=140 \mathrm{ft}$ & $\mathrm{L}=280 \mathrm{ft}$ \\
No. & $m, n$ & $\mathrm{~T}=1.33 \mathrm{ft}$ & $\mathrm{T}=2.66 \mathrm{ft}$ & $\mathrm{L}=2.66 \mathrm{ft}$ \\
\hline 1 & 1,0 & 14.23 & 7.12 & 7.12 \\
2 & 1,1 & 14.62 & 7.88 & 7.31 \\
3 & 1,2 & 15.80 & 9.96 & 7.90 \\
4 & 1,3 & 17.55 & 12.89 & 8.77 \\
5 & 1,4 & 19.75 & 16.64 & 9.87 \\
6 & 1,5 & 22.43 & 21.38 & 11.22 \\
7 & 1,6 & 25.60 & 27.20 & 12.80 \\
8 & 1,7 & 29.28 & 34.16 & 14.64 \\
9 & 1,8 & 33.48 & 42.27 & 16.74 \\
10 & 1,9 & 38.23 & 51.56 & 19.11 \\
\hline
\end{tabular}

$\mathrm{H}$, plate height; $\mathrm{L}$, plate length; $\mathrm{T}$, plate thickness; plate elastic modulus $=4 \times 10^{8} \mathrm{lb} / \mathrm{ft}^{2}$; Poisson's ratio $=0.15$; mass density $=130 \mathrm{lb} / \mathrm{ft}^{3} ; m$ is the mode number along the height; and $n$ is the mode number along the length. Adapted from Wanbourton (1954).

(with slight viscous damping to control resonant amplitudes). The frequency sweep (Alampalli, 1990) showed that (Fig. 7) the 30-ft uniform height wall dispayed two main resonances in both its computed 3-D and plane-strain responses. Hence, walls of uniform height can be modeled using plane-strain analysis. In general, contribution of modes involving spatial variation along the length (between the first and second mode given by plane-strain analysis) might be negligible for most typical walls.

The two walls of variable height (Fig. 7) displayed additional resonances that correspond to modal configurations along the wall length (Figs. 5, 6). These resonances were not excited by the imparted uniform base excitation for the constant height walls (walls 1 and 4 of Fig. 7). Hence, a dynamic plane-strain analysis of structures such as wing walls (where the height varies continuously along the wall length) may not be satisfactory and a 3-D analysis might be necessary.

As may be noted, only one finite element was used along the wall thickness. The effect of this crude representation along the thickness was investigated (Alampalli, 1990) in four different cases (with 1 to 4 elements along the wall thickness). It was found that number of elements along the thickness had a minor effect on the results reported herein (natural frequencies, mode shapes, and modal participation factors). 
$\mathrm{H} 1$ Elevation View

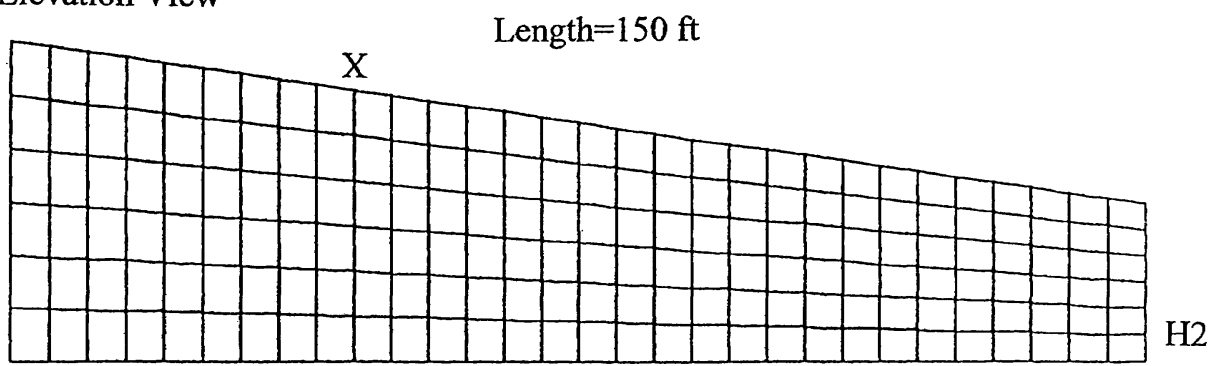

Fixed Base

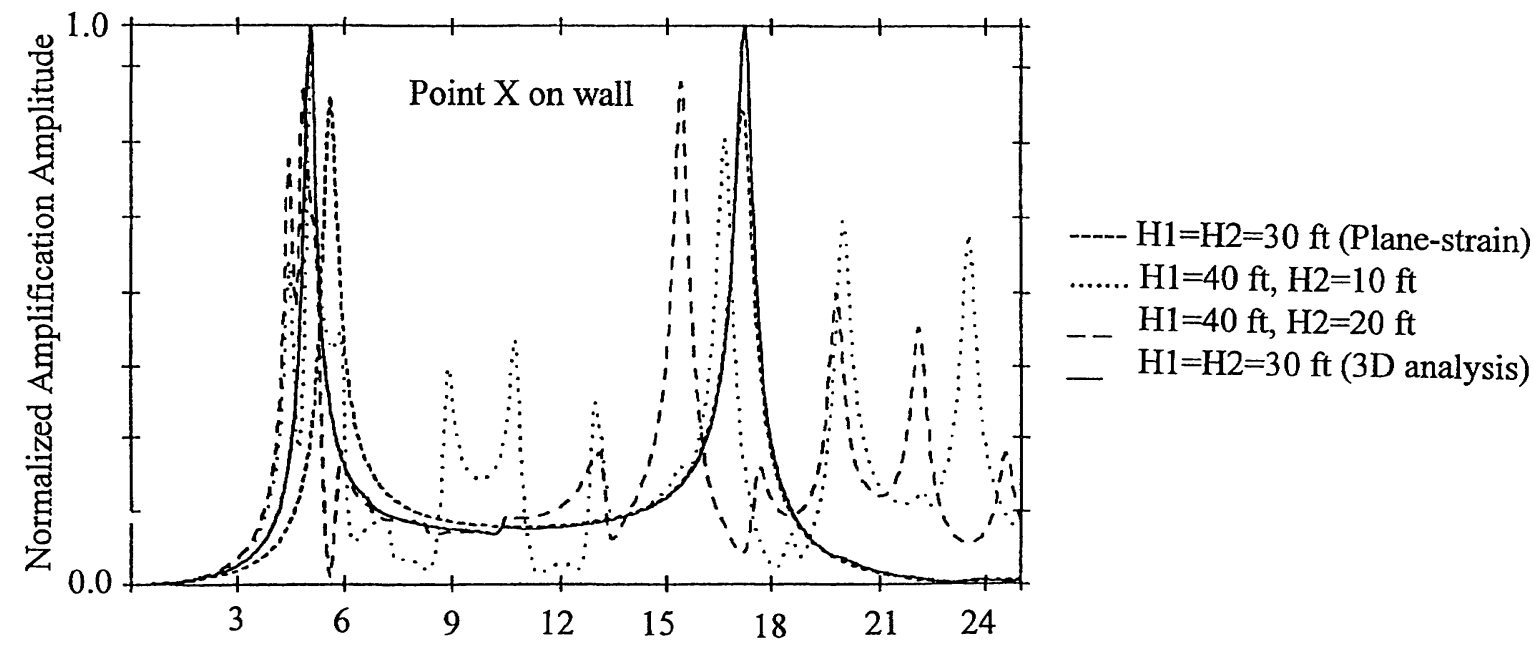

Frequency $(\mathrm{Hz})$

FIGURE 7 Computed Fourier amplitude spectrum of wall response.

\section{PLATE ANALYSIS}

The influence of wall and backfill length and height on dynamic response may be visualized using a simple plate theory idealization (Wanbourton, 1954). In this idealization, the resonances of a wall modeled as a cantilever plate illustrate the effect of length and height (Table 5). The results reveal that the fundamental frequency of the wall is governed by the height and wall length plays no roll in this respect. As the wall length increases, additional low frequency modes appear (along the length). As mentioned earlier, these modes may play an important role in the seismic response of nonuniform height walls.

\section{CONCLUSIONS}

The conducted testing program and associated study showed that additional 3-D resonances play an important role in the seismic response of wall backfill soil systems of variable height (such as highway wing walls). For typical uniform height wall systems (with free vertical edges), modal configurations that display spatial variability along the wall length will only be excited by nonuniform seismic motions. Hence, the seismic response of uniform height walls may be adequately analyzed using a 2-D or plane-strain model. Variable height walls are more accurately represented by a 3-D model.

\section{Acknowledgments}

This research was supported by NCEER Contract 901506 under NSF Master Contract ECE-86-07591. Dr. Paul Van Laak played a major role in conducting the full-scale testing program.

\section{REFERENCES}

Alampalli, S., 1990, "Earthquake Response of Retaining Walls: Full Scale Testing and Computational Modeling," Ph.D. Thesis, Rensselaer Polytechnic Institute, Troy, NY. 
Alampalli, S., Fu, G., and Dillon, E. W., 1995, "Measuring Bridge Vibration for Detection of Structural Damage," Research Report 165, FHWA/NY/RR-95/165, Engineering Research and Development Bureau, New York State Department of Transportation, Albany, NY.

Aliev, H., Mamedov, H., and Radgabova, T., 1973, "Investigation of the Seismic Pressure of Soils on the Retaining Walls and Interdependence Between Foundation Soils and Construction," Proceedings of the Symposium on Earth \& Earth Structures Under Earthquake \& Dynamic Loads, India, pp. 3-10.

Amano, R., Azuma, H., and Ishii, Y., 1956, "Aseismic Design of Quay Walls in Japan," Proceedings of the World Conference on Earthquake Engineering, Berkeley, CA, pp. 32.1-32.16.

Arias, A., Sanchez-Sesma, F. J., and Ovando-Shelley, E., 1981, “A Simplified Elastic Model for Seismic Analysis of Earth-Retaining Structures with Limited Displacements," Proceedings of the International Conference on Recent Advances in Geotechnical Earthquake Engineering and Soil Dynamics, Rolla, MI, pp. 235-240.

Calciati, F., Castoldi, A., Fanelli, M., and Mazzieri, C., 1977, "In Situ Tests for Determination of the Dynamic Characteristics of Some Italian Dams," Proceedings of the Sixth World Conference on Earthquake Engineering, Vol. III, India, pp. 2823-2828.

Chang, C. Y., Power, M. S., Mok, C. M., Tang, Y. K., and Tang, H. T., 1990, "Analysis of Dynamic Lateral Earth Pressures Recorded on Lotung Reactor Containment Model Structure," Proceedings of the 4th National Conference on Earthquake Engineering, Vol. 3, Palm Springs, CA, pp. 643-652.

Douglas, B. M., and Reid, W. H., 1982, "Dynamic Tests and System Identification of Bridges," Journal of Structural Division, ASCE, Vol. 108, No. ST10, pp. 2295-2312.

Elgamal, A.-W., Alampalli, S., and Van Laak, P., 1996, "Forced Vibration of Full-Scale Wall-Backfill System," Journal of Geotechnical Engineering Division, ASCE, Vol. 122, No. 10, pp. 849-858.

Elgamal, A.-W., Van Laak, P., and Alampalli, S., 1990, "Modal Response of Earth Retaining Structures," Proceedings of the Eighth International Modal Analysis Conference, Kissimmee, FL, Vol. I.

Ewins, D. J., 1984, Modal Testing: Theory and Practice, Wiley, New York.

Fukuoka, M., and Imamura, Y., 1984, "Researches on Retaining Walls During Earthquakes," Proceedings of the Eighth World Conference on Earthquake Engineering, San Francisco, CA, Vol. 3, pp. 501-508.

Jennings, P. C., 1971, Engineering Features of San Fernando Earthquake, February 9, 1971, Earthquake Engineering
Research Laboratory, California Institute of Technology, Pasadena, CA.

Keightley, W. O., 1966, "Vibrational Characteristic of an Earthdam," Bulletin of Seismological Society of America, Vol. 56, No. 6 pp. 1207-1226.

Matsuo, H., and Ohara, S., 1960, "Lateral Earth Pressure and Stability of Quay Walls During Earthquakes," Proceedings of the Second World Conference on Earthquake Engineering, Tojyo, Japan, Vol. 1, pp. 165-181.

Paskalov, T. A., Petrovski, J. T., Jurukovski, D. V., and Taskovski, B. M., 1977, "Forced Vibration Full-Scale Tests on Earth-Fill and Rock-Fill Dams," Proceedings of the Sixth World Conference on Earthquake Engineering, India, Vol. III, pp. 2829-2834.

Seed, H. B., and Whitman, R. V., 1970, "Design of Retaining Structures for Dynamic Loads," Lateral Stresses in Ground and Design of Earth Retaining Structures, Specialty Conference, pp. 103-145.

Sitar, N., 1995, Geotechnical Reconnaissance of the Effects of the January 17, 1995, Hyoken-Nanbu Earthquake, Japan, Report UCB/EERC-95/101, Univ. of California at Berkeley, Berkeley, CA.

SMS, 1987, Modal 3.OSE Modal Analysis System, Structural Measurement System, Inc., CA.

Tatsuoka, F. et al., 1996, "Performance of Soil Retaining Walls for Railway Embankments," Soils and Foundations, Special Issue on Geotechnical Aspects of the January 17, 1995, Hyogo-ken Nanbu Earthquake, Japan, Japanese Geotechnical Society, No. 1.

Velestos, A. S., Parikh, V. H., and Younan, A. H., 1995, "Dynamic Response of a Pair of Walls Retaining a Viscoelastic Solid," Earthquake Engineering and Structural Dynamics, Vol. 24, pp. 1567-1589.

Wanbourton, G. B., 1954, "The Vibration of Rectangular Plates," Proceedings of the Institution of Mechanical Engineers, Vol. 168.

Whitman, R. V., 1991, "Seismic Design of Earth Retaining Structures (State of the Art Paper)," Proceedings of the Second Intl. Conference on Resent Advances in Geotechnical Earthquake Engineering and Soil Dynam$i c s$, in S. Prakash, St. Louis, MO.

Whitman, R. V., and Christian, J. T., 1990, "Seismic Response of Retaining Structures," Symposium on Seismic Design for World Port 2020, Port of Los Angels, San Pedro, CA.

Wood, J. H., 1973, "Earthquake Induced Soil Pressures on Structures”, Ph.D. Thesis, California Institute of Technology, Pasadena, CA.

Wood, J. H., 1975, "Earthquake Induced Soil Pressures on Structures", Bulletin of New Zealand Society of Earthquake Engineering, Vol. 8, pp. 175-186. 

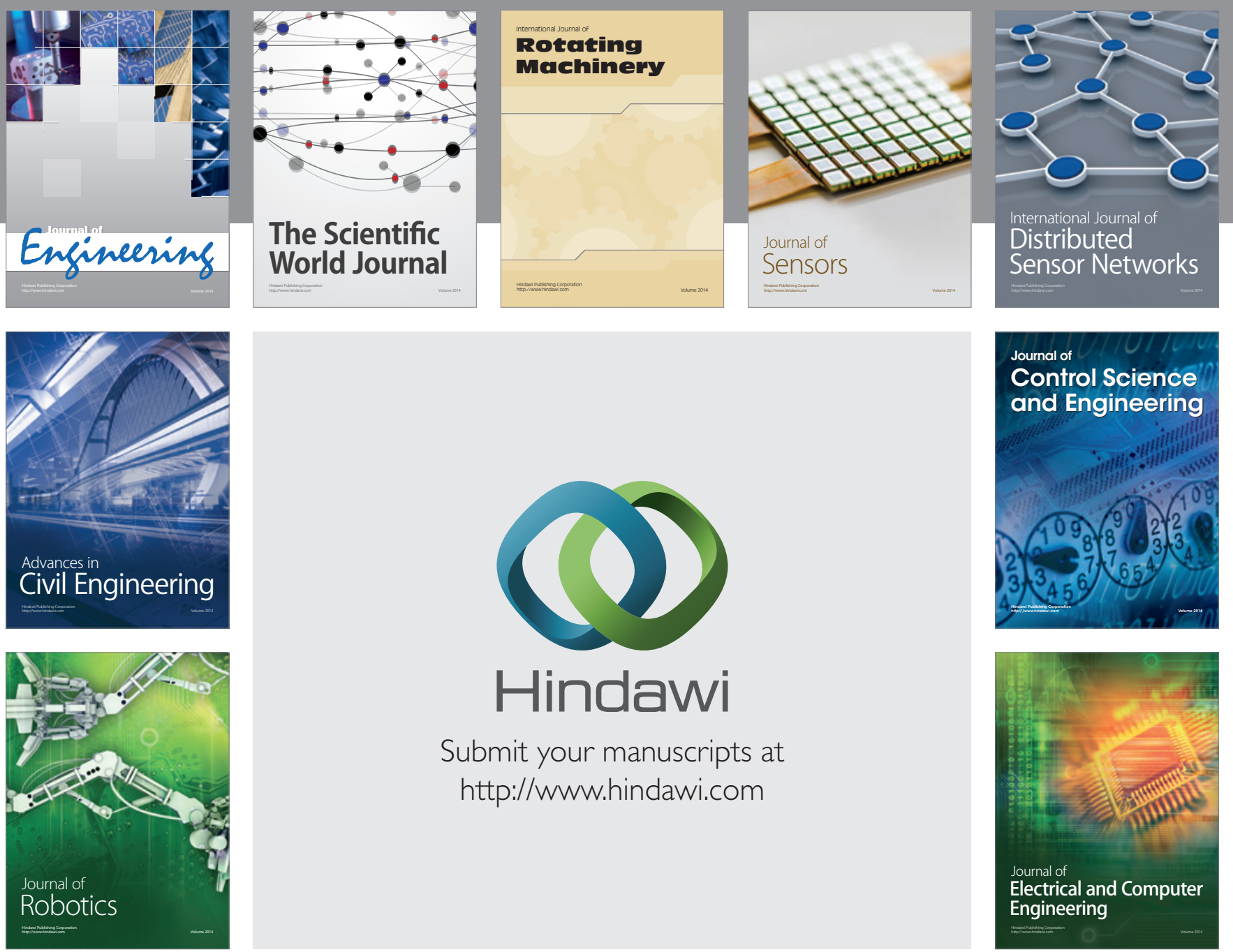

Submit your manuscripts at

http://www.hindawi.com
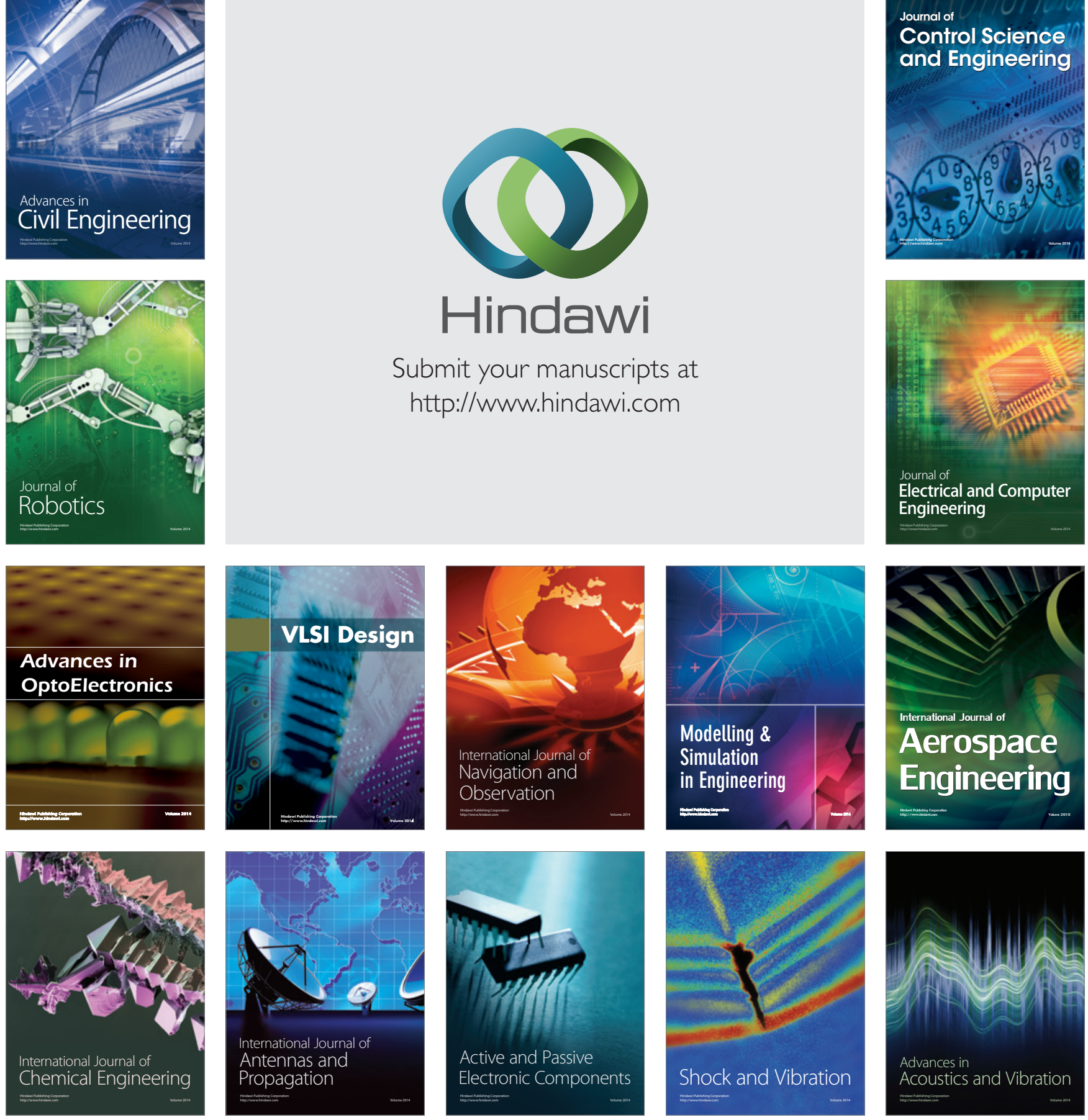